\title{
Promoting the Cultivation of Innovation and Entrepreneurial Talent in Higher Vocational Colleges with the Maker Education
}

\author{
Ping Shen \\ Jiangsu Vocational Institute of Commerce, Nanjing, Jiangsu, 211168, \\ China
}

\begin{abstract}
With the rapid development of social economy, people's way of thinking gradually changes, in order to cultivate more high-quality innovative talents to meet the needs of socio-economic development, and promote the rise and development of maker education. As a new education mode, the maker education mode has caused the transformation of current maker education pattern and the idea. For the maker education, its foundation and prerequisite is the rapid development of information technology, and the integration of the concept of DIY, innovative maker education, project learning and experiential maker education model. This paper mainly makes a detailed analysis and research on three aspects: the overview of the maker education, the role of the maker space in the innovation and entrepreneurship of higher vocational colleges, and the application path of creative maker education in the cultivation of innovative talents in higher vocational colleges. It provides the important reference basis for the better application of creative maker education in cultivating innovative talents in vocational colleges.
\end{abstract}

Keywords: maker education; vocational colleges; innovation and entrepreneurship; personnel training

\section{Introduction}

With the development and progress of science and technology, in many fields and industries are gradually beginning to popularize and promote the large data, cloud 
computing, Internet of things, the Internet and other advanced information technology, the gradual realization of intelligent, which is largely on the promotion of the mode of maker education and the rise and development of maker education, innovation and innovation in maker education has become an important aspect.

\section{The overview of maker education}

\subsection{The concept of maker education}

For the foundation of maker education, the main is the effective integration of advanced information technology. In the hardware facilities, including electronic control / numerical control devices, Arduino open source hardware, 3D printers, Internet, computers and other equipment; in the software facilities, students can expand knowledge and extension to the Internet [1]. In addition, the entity's creative space not only to provide technical platform, but also can use the Internet to set up a virtual network community, thus directly breaking the space restrictions on the original space, a unified platform to effectively connect the various regions of the customers, through exchanges and communication between each other, to learn from each other, rather than "behind closed doors."

\subsection{The value of maker education}

In the course of higher vocational maker education, strengthening the application of creative maker education mode, can better cultivate and develop students' innovation consciousness and innovation ability. For the characteristics of maker education, the main features in eight aspects: First, relevance, refers to the maker education itself and the students themselves, students of the initiative and initiative can be fully mobilized; the second is sufficient Time, students learning and research process have enough time to find relevant issues and information; Third, complexity, referring to the students if you want to complete a certain project, you must integrate the application of multiple aspects of knowledge content; Fourth, the higher investment refers to the students in the maker education, students are more willing to invest more time and energy, the potential of its innovation and entrepreneurship has been the maximum excitation; Fifth, relevance, refers to the mutual cooperation, learning and communication, students can build on the original knowledge framework based on the new knowledge points; Six is the availability of maker education in the blog, to provide students with a wealth of learning resources to meet the needs of all aspects; 7 is sharing, refers to the participation of students in the process, the need to share with others a variety of achievements, knowledge and resources; 8 is novelty, refers to the students in the learning process should break the original mindset, full of the excitation and play an innovative spirit [3]. 


\title{
3 The role of maker space in innovation and entrepreneurship of vocational colleges
}

\author{
3.1 Contribute to the update and optimize of the concept of personnel \\ training
}

At present, students in vocational colleges are not fully aware of the relationship between their own knowledge and innovation and entrepreneurship, and they are not aware of the importance of innovation and entrepreneurship. This is mainly due to the traditional thinking of personnel training Mode restrictions. With the rise and emergence of the culture of creating a guest, a serious impact on the cultivation of talents in vocational colleges' ideas, from the students interpersonal, learning, campus culture and personal careers, growth and learning, Maker culture Focus on sharing, practice, openness and integration of the process of learning and development of students had a serious impact. For Maker culture, the main is to cultivate a sense of innovation, innovation, teamwork ability, a sense of social responsibility, entrepreneurial ability, comprehensive ability of high-quality comprehensive talents, but not a single emphasis on theoretical knowledge And professional skills training [4].

\subsection{Contribute to the changes of traditional teaching model}

In vocational colleges, the unity of the teaching of specialized courses has become a weak link in the current traditional curriculum system, the course content is more outdated, and teaching methods to a certain extent, weakening of the students, the longer the enthusiasm of students to learn and Initiative will be greatly reduced. In the concept of maker education, we need to integrate all kinds of curriculum resources, break the restrictions and boundaries between courses and departments, and fully integrate the professional maker education and general maker education. In addition, the process of teaching and fully highlights the student's dominant position, and to strengthen the relationship between theory and practice, students' comprehensive ability has been significantly improved. With the help of Internet and other advanced teaching equipment, by turning the classroom, Mu classes and other online learning resources, and effectively enrich the content of the course, the learning path to a certain extent, has been expanded.

\subsection{Help the upgrade of entrepreneurship practice platform}

In the traditional practice of innovation and entrepreneurship maker education, although the practice will also be set up the corresponding links, but in fact the main business incubator and entrepreneurial competition in the school-based, with a strong cyclical, and with the initiative to participate in social practice, The game is strong, incomplete records, poor visibility, can query information such as defects. The emergence of Maker culture is the effective way to solve and optimize the problems existing in the practice of traditional entrepreneurship 
maker education, and attach more importance to entrepreneurship, innovation and creative practice in the system of creative activities.

\section{The path of using maker education in innovation and entrepreneurship of vocational colleges}

Higher vocational colleges in China are one of the main platforms for cultivating social talents, and have the responsibility and obligation to cultivate innovative talents. In the innovation and reform of vocational colleges to strengthen the application of the concept of innovative maker education and value for personnel training provides new ideas and opportunities.

\subsection{Promote the change of education concept of teacher from the level of consciousness}

By referring to and drawing lessons from relevant successful experience, higher vocational colleges can also set up relevant research reward fund, which is mainly used to encourage and support the practice and research of the maker education of the creator, which can accelerate the teacher maker education concept to a great extent But also can promote the transformation of teachers' roles. Although the Chinese government has been in the industrial upgrading and economic restructuring in the emphasis on "Peoples innovation and public entrepreneurship", has been "innovation and entrepreneurship" as the whole society people common behaviour and the pursuit of value, but from higher vocational maker education, It is still the school students do not have the relevant potential, but also the ability of students to innovate and entrepreneurship also has a greater difficulty.

\subsection{Promote the integration of internal and external resources from the planning level}

It is necessary to strengthen the integration of internal and external resources from the planning level, which can be divided into three parts: Firstly, the paper introduces the concept,

For the first class in the maker educational activities, it is mainly based on the development of good teaching plan to organize all students to carry out teaching; the second classroom mainly refers to the school, students can use a variety of opportunities and venues to participate in the relevant Innovation and entrepreneurship activities, which is mainly related to student interest, but also through the various activities organized by the school, the students' personality characteristics can be fully developed to help individualized. The effective combination between the two is essentially a combination of individual ability development and common ability, so that in the overall design time, we will be able to better educate the value and philosophy into the specific teaching process, 
and gradually cultivate students' awareness of innovation, innovation habits, innovative thinking and innovation.

On higher vocational maker education and maker education, maker education, the common point between the two is that students attach importance to the ability to practice. The practice platform of cultivating students' ability in school mainly includes project teaching, occupation skill competition, innovation studio, school public creation space, etc. The off-campus practice platform mainly refers to the economic or technological space created jointly by the school and related departments.

The combination of instructors and teams means that the teachers in the team includes both professional teachers in vocational schools, but also should include the relevant industry mentor, has a wealth of experience in innovation and entrepreneurship. Vocational colleges in the professional teachers, the general will have a strong theoretical teaching ability, but the experience in innovation and entrepreneurship is still lacking. For some innovative studio teachers, student skills contest instructor, project teaching teachers, the school should be organized, planned training, which is to quickly enhance the ability of teachers to innovate entrepreneurial capacity and effective ways and means. For the relevant industry mentor, should maximize the school-enterprise cooperation, the advantages of combining work and study, according to the specific training objectives and their own experience targeted training students' innovation and entrepreneurship.

\subsection{Promote the reform of operation mechanism and management system}

It is a systematic project for cultivating students' ability of innovation and entrepreneurship, among which the most important is to fully integrate the value and idea of the maker education in the innovation maker education reform of higher vocational colleges. But it should be noted that, regardless of which way to implement and implement, will to a certain extent, impact and impact on the current teaching order, and sometimes even hinder the school's sustainable development and progress, so the establishment of the corresponding management system and Policy incentive system is very necessary to ensure that the relevant personnel to participate more consciously in the maker education reform, the real culture of innovation and entrepreneurship talent.

Through the construction of teachers, security, personnel training resources, construction, site funding necessary to protect the management of personnel protection, the overall design, etc., to achieve vocational training students to innovate entrepreneurial carrier good run through the relevant measures to fully To stimulate students to participate in the enthusiasm and enthusiasm, and to support and encourage the ability, there are ideas, creative students to participate or participate in a guest lectures, to participate in the practice of innovation, which effectively play the students innovative entrepreneurial vitality, and gradually The formation of benign operating mechanism. 


\section{Conclusion}

With the increasing degree of economic globalization, the current international economic competition is more and more intense and speed up the cultivation of high-quality innovative talents, promoting the construction of an innovative country has become our main task and objectives. Although the development of maker education in China is not long, there is still some unknown, but one thing is certain, in the course of personnel training to strengthen the application of maker education, maker education system reform, curriculum reform as well as the individual development of the students have positive promotion significance, it can promote our country innovation-oriented country's construction process. Therefore, in the process of training talents in higher vocational colleges, it is necessary to strengthen the application of creative maker education.

\section{Acknowledgements}

2015 Key Project of Jiangsu Vocational Institute of Commerce " Maker Space 'and Higher Vocational College Innovation Education' (item number: JSJM15017)

\section{References}

[1] Zhang Tingting. Research on the Cultivation of High-skilled Talents in Higher Vocational Colleges by Means of Innovation and Entrepreneurship. Journal of Liaoning University of Technology (Social Sciences Edition), 55(12), pp.68-70, 2011

[2] He Bin. Innovative Education and Entrepreneurship Education to Cultivate New Tour Guide Talents in the Three Gorges Reservoir Area. Science and Technology Management, 8 (5), pp.87- 91, 2013

[3] Li Jun, Cao Yuping. Study on "Gradual Progressive" Innovation and Education System Construction in Higher Vocational Colleges. Vocational Education Forum, 12(10), pp. 18- 20, 2012

[4] Li Juan, Zhuang Lei. On the Systematic Analysis of the Comprehensive Quality Education and Talent Training in Higher Vocational Colleges - Taking the Innovation and Entrepreneurship Education in Kunming Metallurgy College as an Example. Journal of Kunming Metallurgy College, 9(6), pp.58- 61, 2011

[5] Xu Jiuchun. On the Innovation and Education of Higher Vocational Colleges. Journal of Heilongjiang Ecological Engineering College, 8(4), pp.86-88, 2016 